\title{
LA OBJECIÓN DE CONCIENCIA AL SERVICIO MILITAR EN LA JURISPRUDENCIA POSTCONSTITUCIONAL
}

\author{
MANUEL ALENDA SALINAS \\ DIRECTOR: JOAQUÍN MARTÍNEZ VALLS \\ ACTO DE LECTURA Y DEFENSA: 11 Diciembre 1993
}

La literatura jurídica acerca de la objeción de conciencia al servicio militar ha adquirido en los últimos tiempos una considerable extensión. No obstante, tales obras y estudios, por regla general, se han decantado por amplios planteamientos de tipo iusfilosófico o jurídico-positivista. Pero dejando al margen la Jurisprudencia emanada del Tribunal Constitucional - ampliamente referida por los autores-, estimamos que se echa a faltar un tratamiento doctrinal de la emitida por los demás Tribunales, que no ha sido suficientemente atendida.

La labor que hemos desarrollado se justifica, así, en tratar de abarcar con complitud toda la Jurisprudencia sobre la materia, dictada después de su reconocimiento constitucional, tarea que hasta ahora consideramos que no ha sido realizada. En efecto, si bien son muchos los artículos doctrinales en revistas especializadas - y en las que no lo son tanto-, con diversa altura científica, que se ocupan de la doctrina del Tribunal Constitucional sobre objeción de conciencia al servicio militar; en cambio, respecto de la Jurisprudencia procedente del Tribunal Supremo sobre esta materia, es escaso el interés que se le ha prestado, siendo muy pocos los estudiosos que intentan un análisis de la misma en su integridad. Si descendemos al último escalón, la Jurisprudencia menor, apenas si puede nombrarse un par de autores que citen alguna Sentencia, sin entrar en un análisis más profundo de esta aplicación judicial.

En la medida de nuestras posibilidades (la dificultad en obtener la «jurisprudencia menor» es evidente debido a su falta de publicación, por regla general) estimamos que el esfuerzo desarrollado cumple con estos objetivos.

Justificar el análisis del tema de la objeción de conciencia al servicio militar, no entendemos que requiera de mayores consideraciones que la gran repercusión social de la materia (frecuentemente es noticia que ocupa a los medios de comunicación). Hacerlo desde la perspectiva de un eclesiasticista, huelga por sobradamente conocidas para el estudioso de esta disciplina el que ocupe nuestra atención. Ocuparnos de la Jurisprudencia halla su razón de ser en las causas apuntadas, y en la necesidad de contar con ella —en cuanto aplicación viva del Derecho- para la elaboración jurídica. 
La labor de investigación se estructura, en definitiva, en tres capítulos, examinando la Jurisprudencia emitida, respectivamente, por el Tribunal Constitucional, el Tribunal Supremo y la dictada por órganos judiciales de inferior rango (Tribunales Superiores de Justicia, Audiencias Provinciales, Juzgados de lo Penal) englobada, toda esta última, en el capítulo de Jurisprudencia menor sobre objeción de conciencia al servicio militar.

Todo ello aparece precedido de una breve Introducción en la que, aunque no fuera objeto de nuestra investigación, no podía prescindirse de ciertas premisas de formación en este campo - necesarias para construir nuestro estudio- y que a grandes pinceladas serían: a) El estudio de la relación conciencia-Ley, marco general en el que se sitúa el más concreto de la objeción de conciencia; b) Delimitación conceptual de la objeción de conciencia; y c) El valor de la Jurisprudencia.

El capítulo de Jurisprudencia del Tribunal Constitucional se estructura en dos grandes divisiones, que tienen su punto de separación en la promulgación de las Leyes reguladoras de objeción de conciencia, y que, fundamentalmente, suponen también una distinción en cuanto a las decisiones del Tribunal: La primera referida a recursos de amparo, y la segunda a resolver los trascendentales recurso y cuestiones de inconstitucionalidad interpuestos contra dichas leyes. Entre los puntos más controvertidos de esta Jurisprudencia y que analizamos, cabe señalar: La naturaleza jurídica de la objeción de conciencia al servicio militar, el procedimiento para ser reconocido objetor, la mayor duración de la prestación social respecto del servicio militar, la denominada objeción de conciencia sobrevenida y la penalidad aplicable a los delitos contra el deber de prestación.

El capítulo de Jurisprudencia del Tribunal Supremo aborda, de un lado, cuestiones relativas al desarrollo reglamentario de la materia, objeto de diversas impugnaciones; de otro, la doctrina sentada en supuestos concretos en que se solicita la tutela judicial del pretendido derecho a la objeción de conciencia al servicio militar, no reconocido por el Consejo Nacional de objeción de conciencia. Se trata, básicamente, de supuestos en que los interesados han solicitado el reconocimiento como objetor sin aducir motivo alguno de entre los legalmente preconfigurados. Las negativas administrativas resultantes han sido objeto de recurso con alegación de la vulneración, según casos, de los artículos 14, 16 y 18 de nuestra Constitución. Se estudian también cuestiones como las relativas al silencio administrativo respecto de las peticiones de objeción, la objeción de conciencia sobrevenida y la renuncia a la condición de objetor.

Finalmente, el capítulo relativo a la Jurisprudencia menor atiende, asimismo, dos materias diferentes cuales son la contencioso-administrativa y la penal.

La primera recoge más bien unos apuntamientos sobre la materia, pero que no debían desecharse ya que posteriormente dieron lugar a toda una doctrina del Tribunal Supremo que pone de relieve diversas estrategias seguidas por los objetores. 
La atención se centra - recayendo sobre ella el peso del capítulo- en la jurisprudencia penal. Se afronta el estudio de los tipos penales instaurados por la Ley Orgánica 8/1984, de 26 de diciembre, para reprimir los ilícitos criminales contra el régimen de la prestación social sustitutoria. Se trata de diseñar dichas figuras típicas con el apoyo judicial.

Sobre esta base, hemos pretendido realizar una labor que, revisora de toda la Jurisprudencia, pudiera, con rigor jurídico y apoyo del método interdisciplinar (imprescindible en la materia, jalonada de constitucional, administrativa y penal), sentar unos principios sistemáticos con visos de constructivismo jurídico. Al tiempo, nos ofrece una visión de conjunto sobre las diversas actitudes y estrategias seguidas no sólo por objetores e insumisos, sino también por los órganos administrativos y judiciales, Letrados y representantes del Ministerio Público que han tenido que ocuparse de estos temas. 